\title{
NiTi thermal sprayed coatings characterization
}

\author{
N. Cinca ${ }^{1 \mathrm{a}}$, A. Isalgué ${ }^{2}$, J. Fernández $^{1}$, J. M. Guilemany ${ }^{1}$ \\ ${ }^{1}$ Dep. Materials Science and Metallurgical Engineering, University of Barcelona, Diagonal 649, E-08028 \\ 2 Dep. Física Aplicada UPC, Pla Palau 18, Barcelona E-08003 (SPAIN)
}

\begin{abstract}
NiTi alloy has been particularly studied over many years for its shape memory properties and excellent corrosion resistance and biocompatibility, thus making it suitable for many biomedical applications. Then, bulk material properties have been well characterized depending on the nominal composition, manufacturing method and thermal treatments. It has been, however, less studied the use of such alloy in its overlay form, many times just employing Vacuum Spraying (VPS) for thick coatings in order to avoid Ti oxidation. The present study explores and compares the spraying of atomized NiTi powders by VPS as well as by Atmospheric Plasma Spraying (APS) and High Velocity Oxygen Fuel (HVOF).

$\mathrm{X}$-ray diffraction studies conducted at -100 and $100^{\circ} \mathrm{C}$ revealed that the feedstock powder presented a metastable rhombohedral NiTi phase at low temperatures and at room temperatures and higher the result was beta phase. DSC experiments also supported the previous phase transformations. After spraying, according to the thermal history of the particles in each spraying technology, it is observed the retention of the $\beta$-NiTi feedstock phase as well as the appearance of metastable phases, amorphization and nanocrystalline areas. Also with XRD at different temperatures and, especially in the case of the HVOF coating, due to the moderate heat input of the process, the final results fairly agreed with those of the original powder.
\end{abstract}

\section{Introduction}

NiTi shape memory alloys are widely used in many applications such as actuators, due to their shape memory effect (SME) and super-elastic (SE) behaviours. However, the NiTi alloys have poor cold workability due to their high work-hardening rate [1]. On the other hand, NiTi shows high resistance to wear as well as to cavitation erosion with exceptionally long incubation periods (elapsed cavitation time without measurable mass loss) [2-6]. This feature, related to the shape memory effect, has been understood by the capacity of these materials to absorb energy by the martensitic transformation process. Liang et al. [7] outlined that wear resistance depends on the sum of the pseudo-plastic and pseudo-elastic strain limits and, explained the micro-mechanisms that occur in each case, whenever the material is in one state or the other. They also exclude a possible work-hardening effect owing to the different plastic deformation mechanisms of conventional alloys with that of NiTi. Therefore, for wear applications in SMAs, pseudo-elasticity has been considered the major property. This effect refers to the capacity of SMAs to show a recoverable stress induced martensitic transformation depending on the temperature, as well as to the recoverable reorientation of the martensite orientable domains under stress [1,8-10].

NiTi alloys have been investigated, within the field of thin films, most studies deal with the magnetron sputtering technique $[1,11-12,18]$ and, in the range of thicker coatings, the most used processing method has been Vacuum Plasma Spraying (VPS) [4, 13-19]. Due to the high reactivity of NiTi alloy with oxygen at high temperatures forming oxides, VPS became one of the more exploited techniques. Nevertheless, its extended use has been limited due to the high costs of the process.

Our work has been to further explore the feasibility of other techniques such as High Velocity Oxy-Fuel Spraying (HVOF) and Atmospheric Plasma Spraying and quenching (APS-quenching) to obtain NiTi coatings. The APS-quenching technique consists on a conventional APS gun with an external liquid $\mathrm{N}_{2}$ cooling system.

Apart from the oxidation problem, the less porosity as possible is preferable for this type of coating, especially because its corrosion resistance will be one of the most important properties to be evaluated and it requires a good sealing able to prevent the electrolyte path. Regarding wear resistance in such type of coatings, Stella et al. [20] examined the erosion properties of vacuum plasma sprayed specimens and, although they did not demonstrate that coatings had shape memory, they assumed that despite porosity and second phases not showing this effect, the pseudo-elasticity of stoichiometric NiTi phase played some role on improving the wear resistance.

\footnotetext{
a email: nuria.cinca@ub.edu
} 


\section{Experimental}

The feedstock Ni45\%wt.Ti powder was produced by gas atomization. Low alloyed carbon steel G41350 UNS coupons of $100 \times 20 \times 5 \mathrm{~mm}$ were used as substrates. The substrates were previously degreased in acetone and sandblasted until reaching a roughness about $4 \mu \mathrm{m}$ to provide good mechanical bonding. The coatings were produced using a VPS Plasma System (Sulzer Metco) with F4VB plasma gun; an HVOF system (Diamond Jet Hybrid- DJH2700), and an air plasma spraying gun (F4) from Sulzer Metco with a liquid nitrogen cooling system. This last system allows more rapid solidification reaching cooling velocities as high as $10^{6} \mathrm{~K} / \mathrm{s}$.

A cross-section of each coating was prepared for examination, and these were polished with diamond suspension. Some of them were etched with a $\mathrm{HF}: \mathrm{HNO}_{3}$ solution $(10 \mathrm{~mL} \mathrm{HF}, 25 \mathrm{~mL} \mathrm{HNO} 3,150$ $\mathrm{mL}_{2} \mathrm{O}$ ) to reveal the microstructure and afterwards observed in a scanning electron microscope (JEOL 5510 ) operated at $20 \mathrm{kV}$ with an EDS for microanalysis. X-ray powder diffraction measurements were performed in a Bragg-Brentano $\theta / 2 \theta$ Siemens D-500 diffractometer (radius $=215.5 \mathrm{~mm}$ ) equipped with an A PAAR TTK temperature camera. The used radiation was the $\mathrm{Cu} \mathrm{K} \alpha_{1}$, selected by means of a secondary graphite monochromator. The divergence slit was of $1^{\circ}$ and the receiving slit of $0.05^{\circ}$. The starting and the final $2 \theta$ angles were 10 and $96^{\circ}$ respectively. The step size was $0.05^{\circ}$ in $2 \theta$ and the measuring time of 2.5 seconds per step, in all the experiments. Regarding the wear and corrosion, tests have been carried out according to the ASTM G99-03 and ASTM G65-00 for the Ball-On-Disc and Rubber Wheel tests and, ASTM D-1411 for the electrochemical corrosion test respectively.

\section{Results and discussion}

\subsection{Characterization of the atomized NiTi powder}

The feedstock Ni45\%wt.Ti powder was produced by gas atomization, thus the particles show a spherical morphology (fig. 1a) with a particle size distribution with an asymmetric peak and a broad right end which corresponds to the small amount of particles above 80 microns (fig. 1b); large particles actually have a rougher surface (fig. $1 \mathrm{c}$ ) than the smaller ones (fig, 1d).

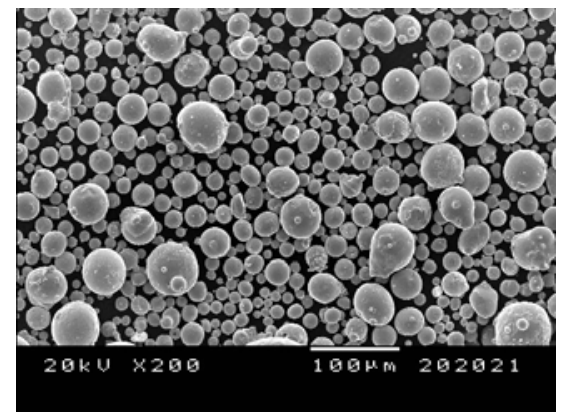

(a)

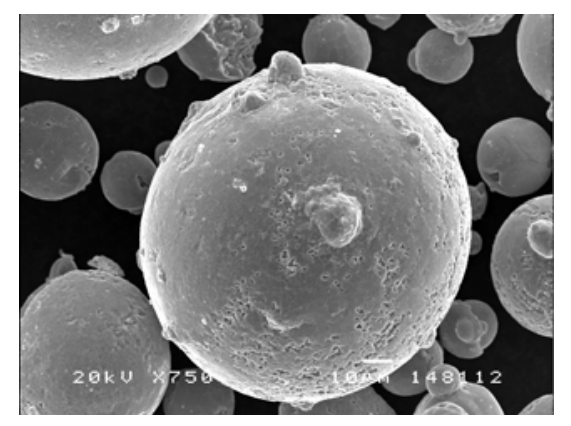

(c)

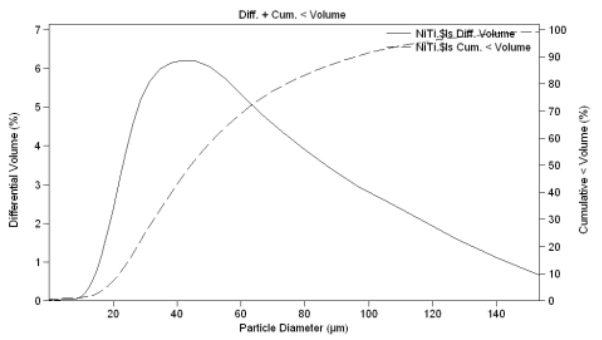

(b)

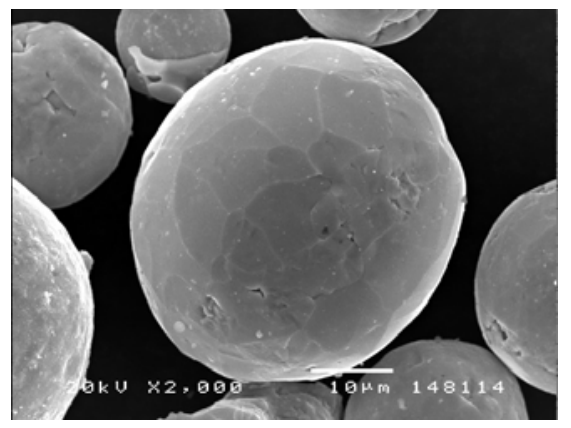

(d)

Fig 1. SEM micrographs of the NiTi powder (a) morphology (b) powder size distribution (c), (d) enlargements of a coarse and small particle respectively. 
By etching, one can see the existence of fine precipitates (fig. 2), which can be identified as $\mathrm{NiTi}_{2}$ or $\mathrm{Ti}_{4} \mathrm{Ni}_{2} \mathrm{O}$-the peak positions of these two phases are identically the same [21]- (fig. 3) in a matrix of austenitic-NiTi beta phase. Both phases could actually have formed: $\mathrm{NiTi}_{2}$ is found besides the NiTi intermetallic compound in the Ni-Ti diagram and, this latter, in turn, exists in a narrow composition range so, when cooling from the liquid state, a small change in composition might lead to this Ti-rich side; also, due to the easy reaction of NiTi with oxygen, the small solubility limit might have been surpassed leading to the formation of $\mathrm{Ti}_{4} \mathrm{Ni}_{2} \mathrm{O}$.

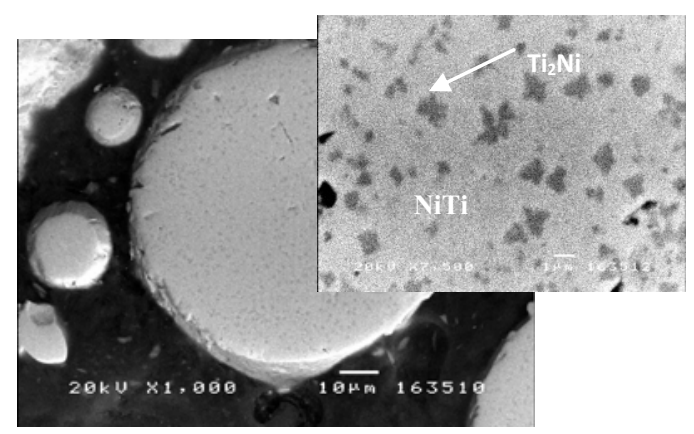

(a)

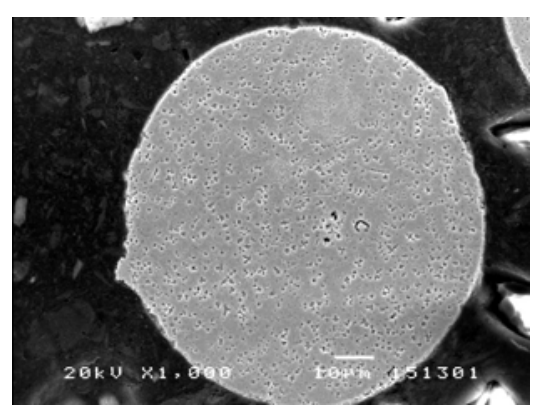

(b)

Fig 2. (a) BSE micrograph of the cross-section (b) SE micrograph of the cross-section etched atomized powder.

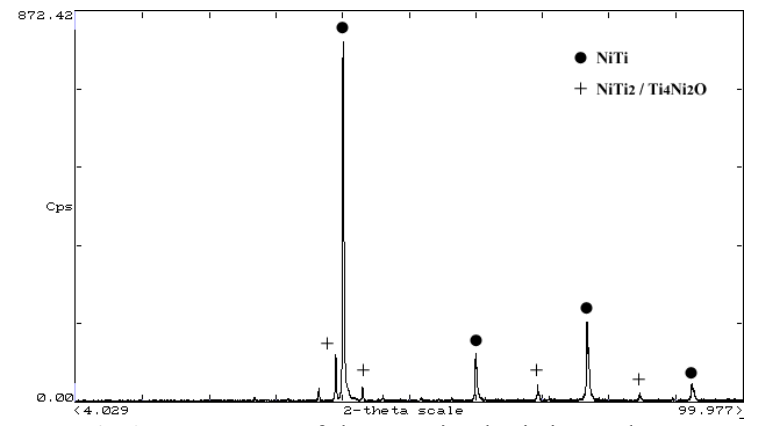

Fig 3. XRD scan of the atomized NiTi powder.

\subsection{VPS, APS and HVOF coatings}

Figures 4, 5 and 6 a show the coating microstructures of VPS, APS+Q and HVOF processes respectively. Neither porosity nor oxidation can be observed in the VPS coating and the splat morphology is only revealed by etching, leading to two distinct kind of areas (fig. 4a); it is not actually clear why ones have been preferentially etched than the others but it seems that the rougher ones are slightly Ti-richer [22]. The X-ray pattern shows the presence of a background typical of amorphization zones; such reasoning was also illustrated in TEM studies.

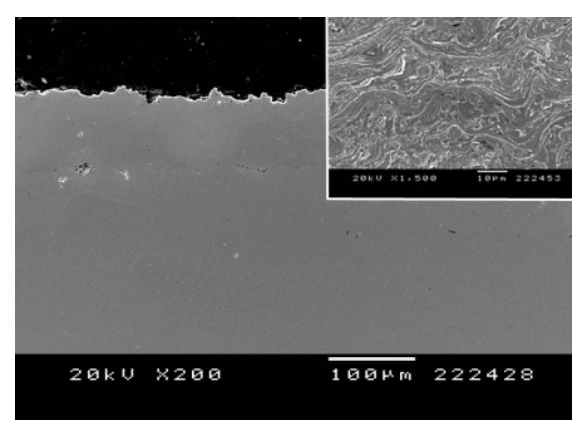

(a)

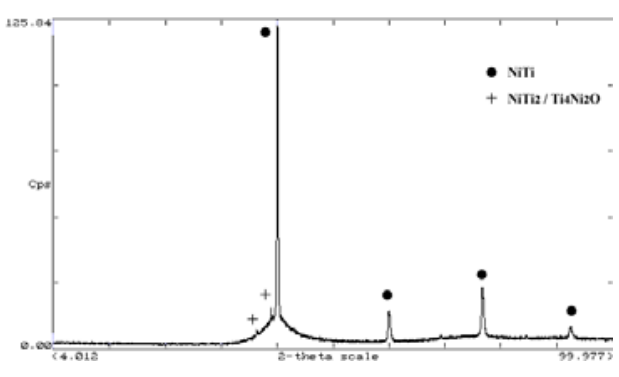

(b)

Fig 4. (a) Micrograph of the unetched VPS coating, with an insert of the revealed microstructure after etching (b) x-ray scan of the coating surface. 
Figure 5 shows the cross section of the APS+Q coating featured by some cracks perpendicular to the plane of splat deposition, which are attributed to the rapid solidification when using the $\mathrm{N}_{2}$ cooling device. The XRD revealed that these NiTi-based coatings were formed by the metaestable TiO as well as beta-phase NiTi (fig. 5b). The broad peaks of the NiTi phase lead to the assumption of nanocrystalline areas, which was also actually confirmed by TEM.

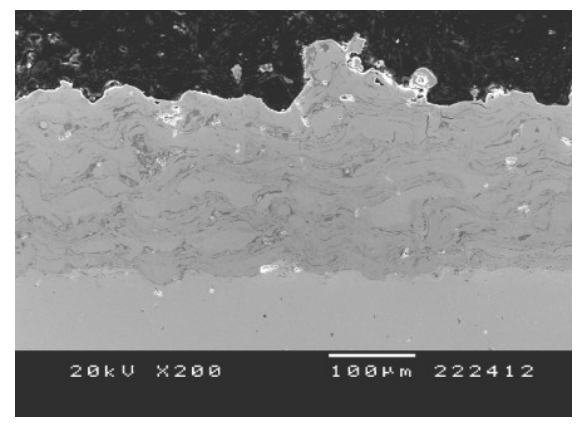

(a)

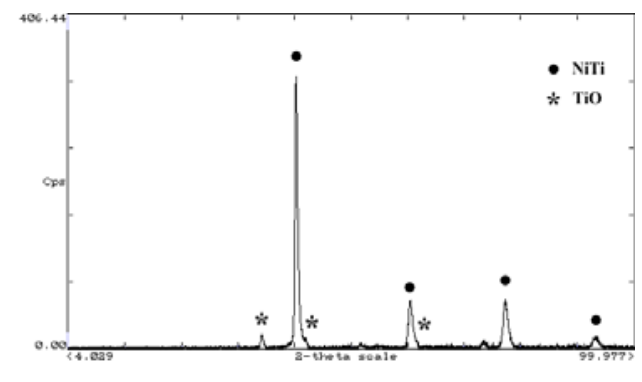

(b)

Fig 5. (a) General micrograph of the APS-quenched cross-section (b) x-ray scan of the coating surface.

By using HVOF, the coating still preserves the powder structure in the coarser particles which are nonfully molten (fig. 6a); this is due to the moderate heat input in this technique compared to the other two. The microstructure here is a little bit more complex than the other two: apart from the beta NiTi and $\mathrm{NiTi}_{2} / \mathrm{Ti}_{4} \mathrm{Ni}_{2} \mathrm{O}$ phases, Ni-rich zones and $\mathrm{Ti}_{2} \mathrm{O}_{3}$ have been also detected. The Ti-depleted areas can be attributed to the oxidation of this element.

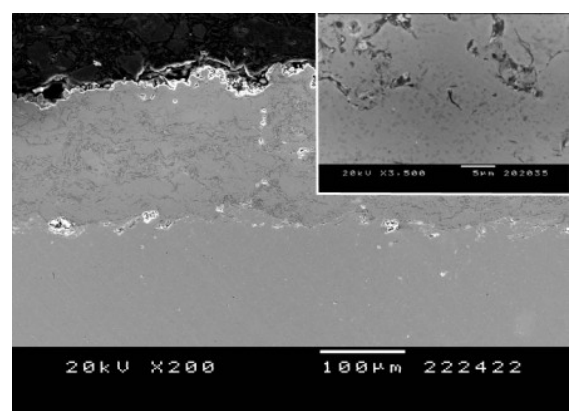

(a)

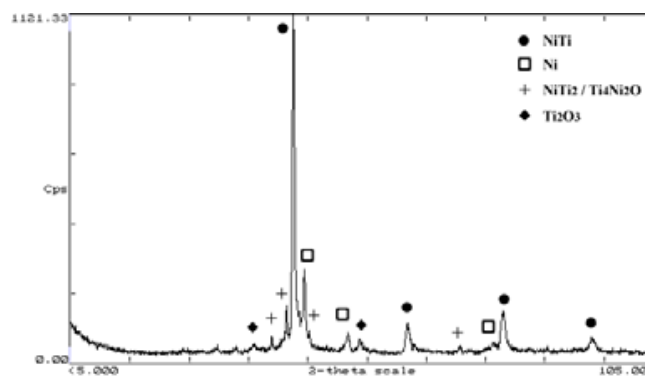

(b)

Fig 6. (a) Micrograph of the HVOF sample cross-section and magnification of its microstructure (b) X-ray scan of the HVOF coating surface.

In order to characterize the phases present at both high and low temperatures around the temperature range where martensitic transformation usually takes place, a calorimetric test (DSC) and XRD diffraction at +100 and $-100^{\circ} \mathrm{C}$ was first carried out. DSC was not conclusive, as it was observed a wide endothermic peak when heating the feedstock powder, but no peak on reverse was appreciated. Some authors also did not observe any peak in the DSC at the heating curve of the as-received NiTi solid solution $[23,24]$. No magnitude of the peak is given because there is large uncertainty in the baseline.

Although nearly the same phases can be identified at the general spectra within the XRD of the NiTi powder at -100 and $+100^{\circ} \mathrm{C}$, a broadening of some of the peaks recorded at $-100^{\circ} \mathrm{C}$ could be appreciated. With a zoom (Fig. 7) these differences are more noticeable. At $-100^{\circ} \mathrm{C}$, the reflections corresponding to the planes $(110)$ and $(-101)$ of the R-phase and (110) of the austenitic $(\beta)$ phase seems to be identified, compared with the diagrams of [25]. 


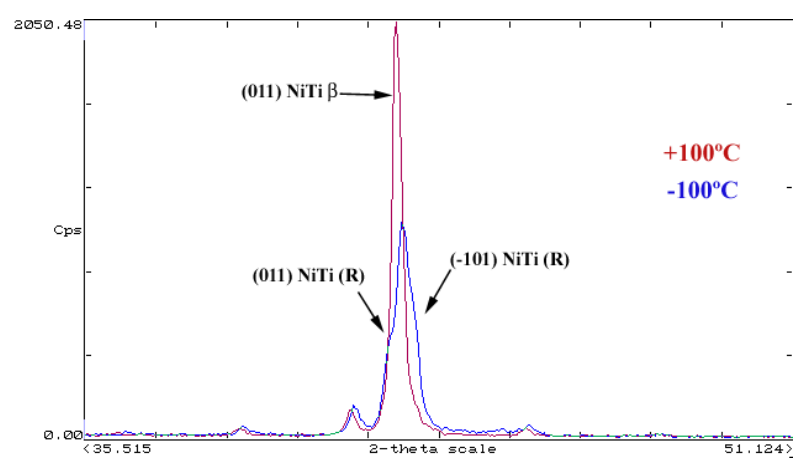

Fig 7. X-ray diffraction at $-100^{\circ} \mathrm{C}$ and $+100^{\circ} \mathrm{C}$ zoom in the scanning range $35^{\circ}<2 \theta<51^{\circ}$.

The calorimetries of the three as-sprayed NiTi powders show the same shape as already observed for the starting powder, without any detectable sharp peak on cooling. By contrast, the XRD did not show clear differences, only the HVOF coating had a somewhat wider peak in the $35-51^{\circ}$ range at $-100^{\circ} \mathrm{C}$, presumably due to some R-phase. R-phase or even B19' martensite could exist at lower temperatures and this would have sense as some areas retain the initial powder structure; for the APS+Q deposit, it is actually complicated as the inherent broadening of the peaks may overlap to the R-phase lines. Stanford et al. [26] did not observe any transformation in NiTi thin films and ascribed it to the small grain size, being below $30 \mathrm{~nm}$; a re-crystallization would then be necessary for the transformations to occur.

\subsection{Mechanical properties of the coatings}

Regarding the three-body abrasion, fairly similar values are obtained and, it is observed a tendency with the material hardness: the hardest deposit (APS-quenching) possesses the lowest wear rate. On the other hand, with regard to the dry sliding behaviour, the highest friction coefficient is that of the VPS coating and the lowest wear rate corresponds to APS-quenching (table 1). By examining the wear tracks, it was concluded that the higher friction coefficient was due to the presence of worn particles entrapped between the two surfaces which behaved as abrasive leading to a more damaging wear effect.

Table 1. Mechanical properties of as-sprayed NiTi coatings.

\begin{tabular}{|lccc|}
\hline & Hardness HV200 & $\begin{array}{c}\text { Abrasive wear rate } \\
\left(\mathrm{mm}^{3} / \mathrm{Nm}\right)\end{array}$ & $\begin{array}{c}\text { Sliding friction } \\
\text { coefficient }\end{array}$ \\
\hline VPS & $496 \pm 20$ & $1.410^{-4}$ & 0.88 \\
\hline APS+Q & $549 \pm 43$ & $9.110^{-6}$ & 0.74 \\
\hline HVOF & $539 \pm 39$ & $2.210^{-4}$ & 0.81 \\
\hline
\end{tabular}

\subsection{Corrosion results of the coatings}

According to the open circuit tests, the electrolyte penetration within the APS+Q proceeds straight to the substrate through the cracks and pores. The VPS and HVOF coatings however, show non-uniform wettability that produces preferential corrosion near the oxides, at the Ti-depleted areas or even, in the case of HVOF, the precipitates observed in the starting powder may also act as potential sites for corrosion. By the potentiodynamic curves, it is observed that the highest anodic passive current corresponds to the APS-quenched sample and the other two (VPS and HVOF) are fairly similar with slightly differences. These results obviously indicate that the APS $+Q$ specimen has increased tendency for corrosion mainly ascribed to the easy electrolyte penetration to the substrate rather than the coating composition. Besides, as the passive potential range of HVOF is lower than the VPS, the first one shows more tendencies for pitting initiation. 


\section{Conclusions}

As a summary, HVOF and APS-quenching (APS+Q) techniques have been evaluated as alternatives to the more expensive VPS procedure for producing NiTi coatings. The new method APS $+Q$ was employed for spraying NiTi powders in a low oxygen atmosphere. Also, HVOF spraying parameters were optimized to obtain the less oxidation as possible. The DSC characterization of the atomized feedstock powder revealed a transformation from R-phase to austenite when heating, but no transformation (or very wide) on cooling. X-ray diffraction patterns at low temperatures confirmed that the R-phase was formed. Within the coatings however, due to some oxidation and structural changes of the powder during the spraying, such transformation was not clearly observed, just some hints identified in the HVOF coating, which retained most of the original core powder structure. Concerning the mechanical and oxidation resistance, the as-sprayed VPS showed the best performance, whereas the APS-Q exhibited lower wear rates, specially ascribed to its higher hardness values, but less oxidation resistance due to cracks.

\section{Acknowledgements}

The authors are grateful to the Generalitat de Catalunya -project 2005SGR00310- and the Ministerio de Educación y Ciencia for the project MAT2006-06025 regarding the support for the work. N. C. acknowledges the researcher grant with reference number AP-2004-2453.

\section{References}

[1] K. Otuska, C.M. Wayman (Eds.), Shape Memory Materials, Cambridge University Press, (1998).

[2] A. Ball, Wear, 91 (1983) pp. 201-207.

[3] Y. Shida, Y. Sugimoto, Wear, 146 (1991) pp. 219-228.

[4] P. Clayton, Wear, 162 (1993) pp. 202-210.

[5] H. C. Lin, S. K. Wu, C. H. Yeh, Wear, 249 (2001) pp. 557-565.

[6] F. T. Cheng, P. Shi, H. C. Man, Mater. Sci. Eng. A, 339 (2003) pp. 312-317.

[7] Y. N. Liang, S. Z. Li, Y. B. Jin, W. Jin, S. Li, Wear, 198 (1996) pp. 236-241.

[8] Otsuka K., Ren X., Progress in Mater. Sci. 50 (2005) 511-678.

[9] http://www.tdcat.cesca.es/TESIS_UPC/AVAILABLE/TDX-0629105-094737//07Sfl07de14.pdf

[10] Itin I., Gyunter V.E., Shabalovskaya S.A., Sachdeva R.L.C., Materials Characterization 32 (1994) 179-187.

[11] Ho K. K., Carman G. P., Thin Solid Films 370, (2000) 18-29.

[12] Yang Y. Q., Jia H. S., Zhang Z. F., Shen H. M., Hu A., Wang Y. N., Materials Letters 22 (1995) 137-140.

[13] Bram M., Ahmad-Khanlou A., Buchkremer H. P., Stöver, Materials Letters 57 (2002) 647-651.

[14] Siegmann S., Halter K., Wielage B. Vacuum plasma sprayed coatings and freestanding parts of Ni-Ti shape memory alloy. ITSC 2003 p 589-595.

[15] Halter K., Sickinger A., Zysset L., Siegmann S., Low Pressure Wire Arc and vacuum Plasma

Spraying of NiTi Shape Memory alloys, Thermal Spray 2003: Advancing the Sicence \& Applying the

Technology. Ed. C. Moreau and B. Marple. Ohio USA, p. 589-595.

[16] Siegmann S., Halter K., Wielage B. Vacuum plasma sprayed coatings and freestanding parts of nit-it shape memory alloy. ITSC 2002 pp 357-361.

[17] Sickinger A., Thermal Spraying of NiTi alloys, SMST-2003: The International Conference on Shape Memory and Superelastic Technologies; USA; (2004) p. 153-162.

[18] Halter K., Sickinger A., Siegmann S., Zysset L., Thermal Spray forming of NiTi shape memory alloys, SMST-2003: The International Conference on Shape Memory and Superelastic Technologies; USA; (2004) p. 163-172.

[19] Nakayama H, Taya M, Smith RW, et al., Mater. Sci. Eng. A 459 (2007) 52-59.

[20] J. Stella, E. Schüller, C. Heissing, O. A. Hamed, M. Pohl, D. Stöver, Wear 260 (2006) 1020-1027.

[21] M. H. Mueller, H. W. Knott, Transactions of the Metallurgical Society of AIME 227 (1963) 674-678.

[22] J. M. Guilemany, N. Cinca, S. Dosta, A.V. Benedetti, Corrosion Science 51 (2009) 171-180.

[23] M. Târcolea, A. E. Dumitru, A. M. Sandu, F. Miculescu, C. M. Cotrut, N. Miculescu, European Cells and Materials 16, Suppl. 1 (2008) p. 57.

[24] A. J. Muir Wood, J-H You, T. W. Clyne, Nanoindentation response of superelastic materials, Smart Materials, Nano- and Micro-Smart Systems: Smart Materials III, Proceedings of SPIE 5648.

[25] S. Miyazaki, K. Nomura, A. Ishida, Journal de Physique IV 5 (1995) p. 777-682.

[26] N. Stanford, S.W. Huang, D. Dunne, Mater. Sci. Eng. A 473 (2008) p. 172-179. 